12

\title{
Снижение потерь мощности в коронном разряде в условиях осадков
}

(ㄷ К.Б. Тыныштыкбаев, Г.Ж. Иманбаев,

А.М. Айнабаев, 3.А. Инсепов

Назарбаев Университет, ЧУ „Nazarbayev University Research and Innovation System“, Астана, Казахстан

I E-mail: zinsepov@nu.edu.kz

Поступило в Редакцию 9 февраля 2018 г.

Приведены результаты высоковольтных испытаний в условиях имитации дождя в коронном разряде образцов алюминиевого провода марки AS 300/39 с покрытиями, синтезированными методом микродугового оксидирования с использованием электролита с добавками оксида графена и углеродных нанотрубок. Показан существенный эффект: до 40\% снижения потерь мощности в короне за счет гидрофильных свойств покрытия.

DOI: 10.21883/PJTF.2018.12.46296.17247

Проблема подавления коронного разряда (CD - corona discharge) является фундаментальной задачей, поставленной еще лордом Кельвином [1], техническое решение которой до сих пор не найдено. Ежегодные мировые потери электроэнергии в коронных разрядах составляют 6 млрд USD в год [2]. Значительные (до 20\%) потери электроэнергии от суммарных потерь электроэнергии в воздушных линиях электропередачи высокого и сверхвысокого напряжений связаны c CD при неблагоприятных погодных условиях: дождь, снег [3].

Настоящая работа выполнена с целью изучения возможности снижения потерь в CD путем нанесения покрытий на поверхность высоковольтных алюминиевых проводов.

Для исследования использовались образцы неизолированного алюминиевого провода марки AS300/39, ГОСТ 839-80 (далее провода), применяемого в высоковольтных $(500 \mathrm{kV})$ воздушных линиях (ВЛ) электропередачи. Синтез покрытий из оксида алюминия $\alpha-\mathrm{Al}_{2} \mathrm{O}_{3}$ осуществлялся методом микродугового оксидирования [4] из электролита с добавками оксида графена (ОГ) и углеродных нанотрубок (УНТ). 
Микродуговое оксидирование образцов провода диаметром $24 \mathrm{~mm}$ и длиной $1500 \mathrm{~mm}$ проводилось при пропускании тока величиной $3 \mathrm{~A}$ через электрод (катод)-электролит-образец провода (анод) при ступенчатой подаче напряжения от 160 до $320 \mathrm{~V}$ с шагом $20 \mathrm{~V}$ в течение $4 \mathrm{~h}$ для каждого образца. Электролиты имели следующий состав: тип ЕI (образец $A 1)-\mathrm{NaOH}(3 \mathrm{~g} / 1), \mathrm{Na}_{4} \mathrm{P}_{2} \mathrm{O}_{7}(4 \mathrm{~g} / 1), \mathrm{Na}_{2} \mathrm{SiO}_{3}(15 \mathrm{~g} / 1), \mathrm{C}_{3} \mathrm{H}_{8} \mathrm{O}_{3}$ $(10 \mathrm{ml} / \mathrm{l}), \mathrm{Al}_{2} \mathrm{O}_{3}(50 \mathrm{mg} / \mathrm{l})$; тип EII (образец $\left.A 4\right)$ - электролит состава EI с добавками суспензии ОГ (2 $\mathrm{mg}$ ОГ/1 $\mathrm{ml} \mathrm{H} \mathrm{H}_{2} \mathrm{O}$ ) (производство Sigma Aldrich, США); тип ЕIII (образец A5) - электролит Е1 с добавками суспензии УНТ (50 g $0.01 \mathrm{wt} \%$ УНТ на $100 \mathrm{ml} \mathrm{C}_{3} \mathrm{H}_{8} \mathrm{O}_{3}$ ) (производство TUBALL, Новосибирск, Россия).

Морфология и элементный состав покрытий исследовались с помощью сканирующего электронного микроскопа Crossbeam 540 Carl Zeiss и рентгеновского флуоренсцентного спектрометра XRF Panalytical AXIOS. Отдельные измерения были проведены с помощью сканирующего электронного микроскопа TESCAN LYRA3 GMH с энергодисперсионным спектрометром EDS X-MAX (Санкт-Петербург).

Результаты элементного XRF-анализа показали, что в основном покрытия состоят из оксидов алюминия $\mathrm{Al}_{2} \mathrm{O}_{3}$ и кремния $\mathrm{SiO}_{2}$ (wt.\%): образец $A 1$ содержит $37.9 \mathrm{Al}_{2} \mathrm{O}_{3}, 45.2 \mathrm{SiO}_{2}, 6.3 \mathrm{P}_{2} \mathrm{O}_{5}$; образец $A 4-$ $36.9 \mathrm{Al}_{2} \mathrm{O}_{3}, 35.4 \mathrm{SiO}_{2}, 9.0 \mathrm{P}_{2} \mathrm{O}_{5}$; образец $A 5-37.1 \mathrm{Al}_{2} \mathrm{O}_{3}, 32.0 \mathrm{SiO}_{2}$, $21.5 \mathrm{P}_{2} \mathrm{O}_{5}$. Суммарное содержание остальных элементов менее $10 \%$, углерод и углеродные соединения используемыми методами XRF и EDS не регистрируются.

Высоковольтные (свыше $100 \mathrm{kV}$ ) испытания проводились в системе электродов провод-плоскость на испытательном полигоне СибНИИЭ (Новосибирск), который имитирует реальные условия возникновения $\mathrm{CD}$ на проводах ВЛ $500 \mathrm{kV}$ в условиях имитации дождя и сухого климата [5].

Результаты высоковольтных испытаний показывают, что образцы с покрытиями более устойчивы к короне, $\mathrm{CD}$ начинают развиваться при бо́льших напряжениях, чем напряжение начала возникновения $\mathrm{CD}$ на образце провода без покрытия (см. таблицу). На образцах $A 1, A 4$ и $A 5$ с покрытиями напряжение начала коронного разряда составляет $V_{\mathrm{CD}}=100 \mathrm{kV}$, а на образце $A 0$ без покрытия $V_{\mathrm{CD}}=80 \mathrm{kV}$ (за начало $V_{\mathrm{CD}}$ принято напряжение при мощности потерь $3 \mathrm{~W}$ ). Наибольшая мощность потерь $P=26.2(26.2) \mathrm{W}$ в короне при рабочем напряжении $V=140 \mathrm{kV}$ наблюдается в образце $A 0$, наименьшие потери $P(A 4)=17.3(17.3) \mathrm{W}$ и 
Характеристики коронных разрядов на образцах провода под дождем

\begin{tabular}{c|c|c|c|c}
\hline \multirow{2}{*}{ Характеристика } & \multicolumn{4}{|c}{ Образец } \\
\cline { 2 - 5 } & $A 0$ & $A 1$ & $A 4$ & $A 5$ \\
\hline Напряжение начала $\mathrm{CD},{ }^{*} \mathrm{kV}$ & $80 / 83$ & $100 / 97$ & $100 / 97$ & $100 / 94$ \\
Напряжение $V, \mathrm{kV}$ & \multicolumn{4}{|c}{ Мощность потерь на корону $P{ }^{* *} \mathrm{~W}$} \\
50 & 0.2 & $<0.1$ & $<0.1$ & 0.6 \\
70 & $0.3(0.2)$ & $0.2(0.4)$ & $0.2(0.8)$ & $0.3(0.4)$ \\
80 & 2.5 & 1.7 & 0.7 & 1.7 \\
100 & $6.8(5.8)$ & $3.3(3.3)$ & $3.5(2.8)$ & $3.7(3.1)$ \\
120 & 16.0 & 10.2 & 9.7 & 11.2 \\
140 & $26.2(26.2)$ & $20.2(19.3)$ & $17.3(17.3)$ & $19.1(16.6)$ \\
150 & 34.6 & 27.2 & 24.8 & 24.6 \\
170 & 55.0 & 46.2 & 46.2 & 43.5
\end{tabular}

* В числителе приводится напряжение начала CD по эопограммам, в знаменателе по потерям на корону при мощности потерь $3 \mathrm{~W}$.

** Без скобок приводятся значения потерь, полученные при подъеме напряжения, в скобках - при снижении напряжения.

$P=19.1(16.6) \mathrm{W}$ имеют место на образцах $A 4$ и $A 5$ соответственно, а в образце $A 1$ потери составляют $P=20.2(19.3) \mathrm{W}$ (без скобок указаны значения мощности потери при подъеме напряжения, в скобках при снижении) (см. таблицу). При рабочем напряжении $V=120 \mathrm{kV}$ испытательного стенда обеспечивалось равенство максимальной напряженности поля на исследуемом образце провода и максимальной напряженности поля на составляющих расщепленного провода $3 \times A S 300 / 39$ ВЛ $500 \mathrm{kV}[5]$.

Наименьшие мощности потерь на $\mathrm{CD}$ наблюдаются в образцах $A 4$ и $A 5$ с покрытиями, синтезированными в электролитах EII и EIII с добавками ОГ и УНТ.

На рис. 1 приведены эопограммы образцов, полученные с помощью электронно-оптического преобразователя „Филин-6“. На них видны очаги возникновения $\mathrm{CD}$ на каплях воды: чем меньше капель воды на проводе, тем меньше очагов $\mathrm{CD}$. Количество очагов $\mathrm{CD}$ на образцах $A 1$, $A 4$ и $A 5$ провода с покрытием значительно меньше, чем на образце $A 0$ исходного провода без покрытия (рис. 1). Высокая антикоронная устойчивость образцов $A 4$ и $A 5$ связана с образованием меньшего числа

Письма в ЖТФ, 2018, том 44, вып. 12 

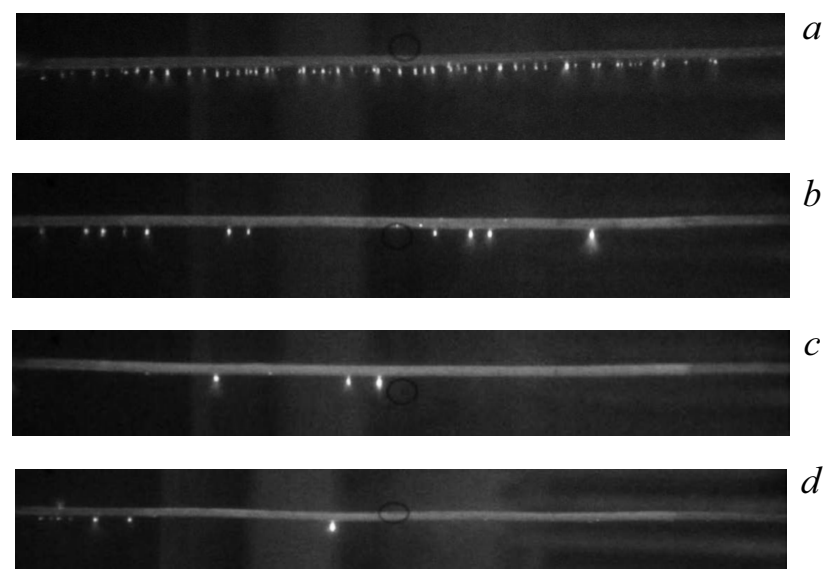

Рис. 1. Эопограммы $\mathrm{CD}$, полученные в условиях имитации дождя при напряжении $80 \mathrm{kV}$ на образцах провода $A 0(a), A 1(b), A 4(c)$ и $A 5(d)$.

очагов CD в виде капель воды, на которых происходит локальное усиление напряженности электрического поля и начинают развиваться $\mathrm{CD}$. Образование капель воды связано со смачиваемостью поверхности покрытий образцов провода.

Эксперименты по изучению смачиваемости покрытий были проведены на контрольных образцах провода диаметром $4 \mathrm{~mm}$ и длиной $180 \mathrm{~mm}$, отделенных от поверхностного витка исследуемых образцов провода. Результаты показали высокую смачиваемость покрытий у образцов $A 4$ и $A 5$. Вес образцов $A 4$ и $A 5$ после смачивания увеличился на 13.5 и $8.5 \mathrm{mg}$ по сравнению с весом образцов $A 1(5.3 \mathrm{mg})$ и $A 0$ $(1.1 \mathrm{mg})$ соответственно.

Высокая смачиваемость покрытий образцов $A 4$ и $A 5$ связана с пористостью поверхности покрытий.

Электронно-микроскопические измерения показывают, что морфология поверхности покрытий зависит от состава электролита. Поверхность покрытия образца $A 1$, полученного в электролите EI, содержит трещины (рис. 2,a). Поверхность образцов $A 4$ и $A 5$, полученных в электролитах ЕII и ЕIII соответственно, является пористой, содержит мелкие поры размером $200 \mathrm{~nm}$. На рис. 2, $b$ показано электронно-

Письма в ЖТФ, 2018, том 44, вып. 12 


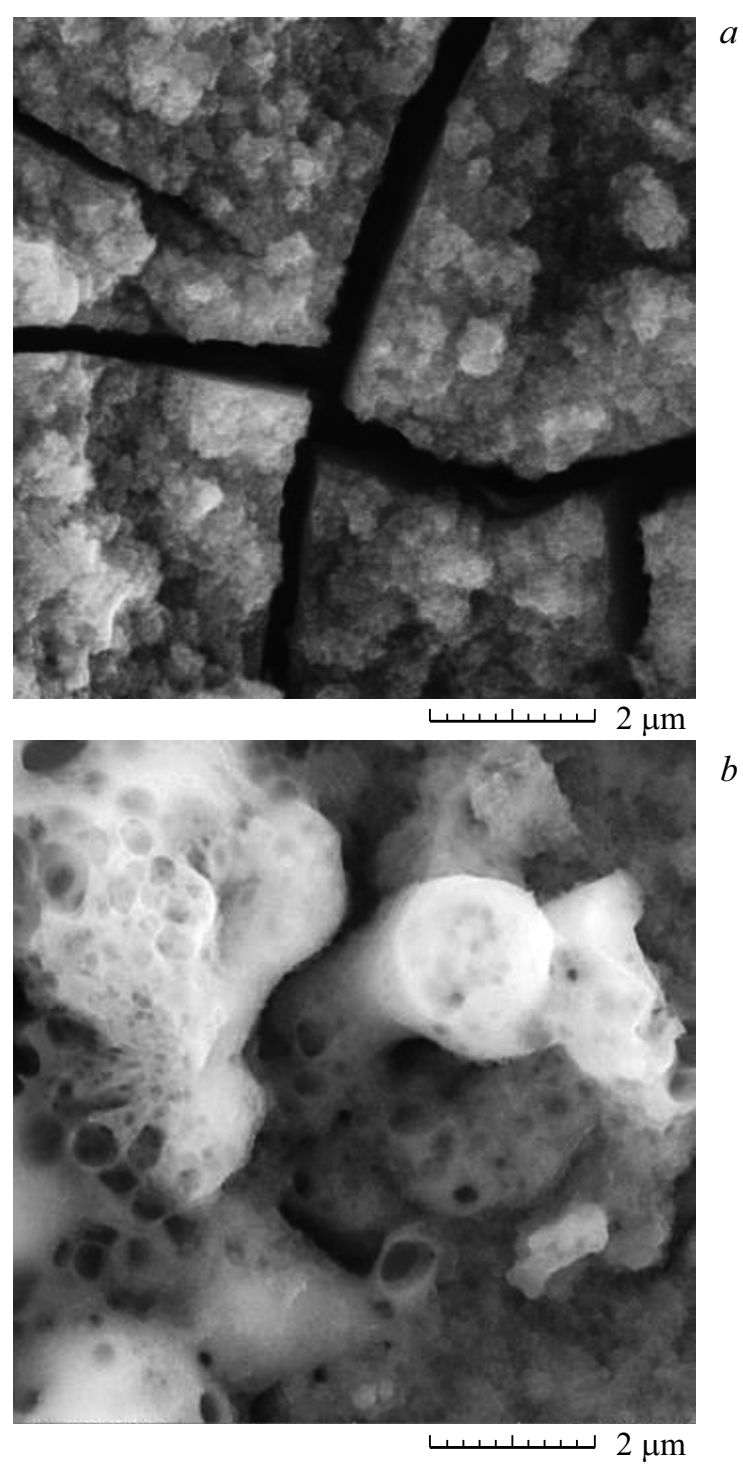

Рис. 2. Электронно-микроскопические изображения поверхности образцов $A 1(a)$ и $A 5(b)$.

Письма в ЖТФ, 2018, том 44, вып. 12 
микроскопическое изображение пор на поверхности образца $A 5$. Аналогичные поры наблюдаются и на поверхности образца $A 4$.

Образцы $A 4$ и $A 5$ показали высокую антикоронную устойчивость из-за гидрофильности покрытий, обусловленной их пористостью. Отсюда следует вывод, что антикоронная устойчивость образцов достигается за счет гидрофильности покрытий, приводящей к росту смачиваемости поверхности водой, при котором происходит устранение или уменьшение локальных очагов короны в виде капель воды на образцах.

Данные покрытия обладают высокой прочностью. Как показывают результаты высоковольтных испытаний при подъеме и снижении напряжения CD (см. таблицу), гистерезисные явления отсутствуют. Мощность потерь в короне на одинаковых ступенях напряжения в процессе его подьема и снижения изменяется незначительно. Это свидетельствует о том, что покрытие провода не деградирует под воздействием электрического поля и коронных разрядов.

Кроме того, результаты длительной выдержки образцов после испытаний на открытом воздухе в дождь, снег, сильные морозы показали устойчивость покрытий к внешним воздействиям погоды.

Таким образом, результаты высоковольтных испытаний в условиях имитации дождя показали высокую антикоронную устойчивость образцов алюминиевого провода марки AS300/39 с покрытиями на основе высокотемпературного оксида алюминия $\alpha-\mathrm{Al}_{2} \mathrm{O}_{3}$, модифицированного оксидом графена и углеродными нанотрубками. Такая устойчивость достигается за счет гидрофильности полученных покрытий, приводящей к росту смачиваемости поверхности водой, при котором происходит устранение или уменьшение локальных очагов короны.

Работа финансировалась АО „КEGOC““ (договор № 192) и частично ЧУ „Nazarbayev University Research and Innovation System“ (договоры № 111, 268 и 282).

\section{Список литературы}

[1] Thomson W., Larmor J. // Mathematical and physical papers. Cambridge: University Press., 1911. V. 6. P. 211-215.

[2] Stability vs. Power Loss - Cost Considerations; http://www.ofilsystems.com/articles/cost $\% 20$ considerations.html 
[3] Шаров Ю.В., Гаджсиев М.Г. // Электро. 2010. № 3. С. 19-23.

[4] Погребняк А.Д., Каверина А.Ш., Кылышканов М.К. // Физикохимия поверхности и защита материалов. 2014. Т. 50. № 1. Р. 72-88.

[5] Высоковольтный испытательный комплекс СИБНИИЭ (информационный материал). Новосибирск, 2001. 10 с.

Письма в ЖТФ, 2018, том 44, вып. 12 